\title{
Witnessing violence in early secondary school predicts subsequent student impairment
}

\author{
Michel Janosz, ${ }^{1,2,3}$ Frédéric N Brière, ${ }^{1,4}$ Benoît Galand, ${ }^{5}$ Sophie Pascal, 1,2 \\ Isabelle Archambault, ${ }^{1,2,3}$ Marie-Christine Brault, ${ }^{2,6}$ Brigitte Moltrecht, $^{7}$ \\ Linda S Pagani,
}

- Additional material is published online only. To view please visit the journal online (http://dx.doi.org/10.1136/ jech-2018-211203).

'École de Psychoéducation, Université de Montréal, Montréal, Quebec, Canada Group (SERG), Université de Montréal, Montréal, Quebec Canada

${ }^{3}$ Institut de Recherche en Santé Publique de I'Université de Montréal (IRSPUM), Montreal,

Quebec, Canada

${ }^{4}$ Équipe Renard, Université de Montréal, Montréal, Quebec, Canada

${ }^{5}$ Psychological Sciences Research Institute (IPSY), Université Catholique de Louvain, Louvain-la-Neuve, Belgium

${ }^{6}$ Université du Québec à Chicoutimi, Saguenay, Quebec Canada

${ }^{7}$ Ministère de l'Éducation Nationale, de l'Enseignement supérieur et de la Recherche, Tours, France

Correspondence to Dr Michel Janosz; michel.

Received 18 June 2018 Revised 9 August 2018 Accepted 12 August 2018 Published Online First 16 September 2018 ${ }^{2}$ School Environment Research janosz@umontreal.ca

\begin{abstract}
Background Past research suggests that adolescents who witness violence are at risk of adjustment problems. However, few studies have implemented a longitudinal design and have accounted for direct experiences of victimisation and other major confounders. This prospective study examines the relationship between witnessing school violence and subsequent impairment and whether such associations depend on the kind of violence witnessed.
\end{abstract}

Methods 3936 adolescents from Quebec (Canada) were followed from ages 12 through 15 years. Linear regression tested associations between witnessing school violence at age 13 and subsequent antisocial behaviour (drug use, delinquency), emotional distress (social anxiety, depressive symptoms) and academic adjustment (school achievement, engagement) at age 15. We compared the relative contribution of differing forms of witnessing school violence versus being victimised directly.

Results General school violence predicted later impairment. The adjusted associations between indirectly experiencing violence as a bystander and subsequent impairment were comparable to those of direct victimisation. Witnessing covert and major violence was associated with drug use and delinquency. Witnessing minor violence was associated with increases in drug use, social anxiety, depressive symptoms and decreases in school engagement.

Conclusions Almost all students witnessed school violence, which predicted impairment. Witnessing violence was associated with risk of subsequent adjustment problems 2 years later. Directly experienced victimisation showed a comparable magnitude of risk. This suggests that when it comes to symptoms of conduct disorder, witnessing violence might have the same impact as experiencing it directly. Witnessing earlier covert and major violence predicted social impairment whereas minor violence predicted psychological and academic impairment.

\section{INTRODUCTION}

(C) Author(s) (or their employer(s)) 2018. No commercial re-use. See rights and permissions. Published by BMJ.

To cite: Janosz $\mathrm{M}$,

Brière FN, Galand B, et al. J

Epidemiol Community Health 2018;72:1117-1123.
The school community can be stressful for some students. It is a matter of academic performance and a matter of navigating its social jungle unscathed. School violence represents a global phenomenon. ${ }^{1}$ The WHO reports that $40 \%, 38 \%$ and $36 \%$ of 13 year-olds from 28 countries had respectively fought, bullied others and been bullied by others at school in recent months. ${ }^{2}$ In a recent report on
American students between ages 12 and 18, there were 1420900 non-fatal events of violence during the 2012-2013 school year. ${ }^{3}$ Two-thirds of these were classified as violent events on school property. When young people experience aggression, either as perpetrators or victims, they face a lifecourse mental health risks. ${ }^{45}$ Adolescent indicators of psychosocial impairment have a long-term negative influence on personal and economic success. ${ }^{6-8}$ In this respect, school violence remains a critical public health issue because it simultaneously affects individuals, families and communities.

Compared with the substantial database on victims of school violence, few studies have addressed psychological and social outcomes of witnessing school violence. Paradoxically, as many as $90 \%$ of typically developing students witness school-related violence, either as innocent bystanders or guilty spectators. ${ }^{9-11}$ There is growing concern that witnessing violence might have harmful consequences during adolescence, a critical period in human development.

Adolescence represents a critical and challenging developmental period mostly because it involves identity formation and cognitive maturation in a school context that is both diverse and segregated. $^{12} 13$ The daily experience of identity uncertainty and frequent reflex to give importance to the perspective of others, which are equally normative, generates considerable psychological strain. ${ }^{12}$ Given this developmental context, exposure to violence within an immediate or larger social group would be theoretically traumatic during adolescence.

Violence towards others aims to directly or indirectly cause physical or psychological discomfort. ${ }^{11}$ We contend that school violence may be classified in three categories ${ }^{10}{ }^{15}$ : (1) covert violence, which includes concealed acts involving objects that reach the awareness of witnesses only after they are committed (eg, vandalism, theft); (2) minor violence, which includes frequent, but modest acts directed at people (eg, verbal insults and threats); and (3) major violence, which includes rare, but severe acts directed at people (eg, physical assault). Behaviours and motives within all three categories characterise bullying-victimisation experiences at school. ${ }^{4}$ Although the risks of experiencing violence in multiple contexts have been documented in youth, ${ }^{9}$ the impact of different forms of violence within the school context has not been addressed. The level of psychological disturbance is likely 
proportional to the severity of violence observed, as suggested by past cross-sectional research. ${ }^{59}$

Several cross-sectional studies have found associations between witnessing school violence and somatic complaints, depression, anxiety, substance use and school absenteeism and suspension. ${ }^{9}{ }^{15-19}$ Although these findings seem logical, cross-sectional designs do not rule out pre-existing personal or sociodemographic characteristics that could act as alternative or competing explanations. Longitudinal designs with measures prior to experienced violence offer better control for potential confounding. Such designs have been sparse and have indicated associations between witnessing school violence and underachievement, disengagement, emotional distress and conduct problems. ${ }^{10} 1120$

Although the few existing studies corroborate the suggestion that indirect school violence exposure exerts risks of psychosocial impairment on affected youth, they remain characterised by modest samples, limited outcomes, time frame restrictions and/ or lack of control for key confounders. ${ }^{101120}$ Noteworthy is that such studies are plagued by potential confounders, going beyond gender and level of access and control over wealth. Specifically, most important among these would be having been a victim of school violence, aggressive, associated with deviant peers, in a home characterised by family dysfunction, or marginalised by poor grades and cognitive vulnerability. ${ }^{10} 11$ Some school environments are more aggressive than others, ultimately affecting student perception. Consequently, direct exposure to school violence (in the role of victim), ${ }^{20}$ prior school adjustment ${ }^{11}$ and variations in school-level violence should ideally be considered as competing explanations. ${ }^{10} 1120$ Longitudinal research has provided conflicting findings regarding long-term associations with school achievement and conduct problems. It also remains unknown whether such outcomes depend on the kind of violent events witnessed by bystanders. ${ }^{1621}$

In response to the above concerns, this study prospectively examines whether witnessing school violence at age 13 predicts subsequent self-reported indicators of psychosocial impairment at age 15 , while adjusting for a comprehensive set of potential confounders. We further examine the distinct relative risks associated with exposure to covert, minor and major violence. It is hypothesised that witnessing violence will be associated with psychosocial impairment risk and proportional to the observed intensity. $^{22}$

\section{METHODS}

\section{Participants and procedure}

The initial sample for this project approved by the Institutional Review Board conducted at the University of Montreal comprises a cohort of 9713 adolescents followed annually from age 12 years (grade 7; 2003/2004 school year) through age 15 (grade $10 ; 2007 / 2008$ school year) in 77 schools across the province of Quebec (Canada). Schools were selected using stratified random sampling and were thus representative in terms of disadvantaged geographical location, size, first language and provincial demographics (86.2\% Caucasian and 52.6\% women). Consent was provided by $77 \%$ of eligible participants. Trained teachers and research assistants administered youth self-report questionnaires in class. From the initial 9713 participants, we excluded 2598 students who did not complete the school violence questionnaire at age 13 years (grade 8 ), as we could not infer their exposure to school violence. Second, to limit attrition bias, we also excluded schools with (1) unusually low participation rates on outcomes at age 15 years (grade $10, n=8$ schools $=1639$ students) and (2) schools that did not cover the entire secondary school period ( $\mathrm{n}=17$ schools $=1540$ students). Outcomes at age 15 years were missing for $22 \%-28 \%$ of remaining participants. The final sample comprised 3936 students, with more girls (52.1\%) than boys (47.9\%). The majority of participants were Quebec born (95.4\%) and attended a French language school $(83.2 \%)$. Forty-one schools were in disadvantaged communities and 11 schools were in average socioeconomic status communities. Written informed consent was obtained by all participants and their parents.

\section{Measures: predictor (age 13.4 years, grade 8 )}

Witnessing school violence was treated using a global and specific analytic strategy. General school violence was measured using a global 9-item frequency scale $(\alpha=0.85)$ asking students to report whether they observed, or were informed, of nine kinds school violence $(0=$ never to $4=$ almost every day $) .{ }^{10}$ This global factor comprises three subfactors which address both type and severity of exposure: covert violence (theft, vandalism; $\alpha=0.76$ ); minor violence (verbal insults between students and directed towards teachers, verbal threats between students; $\alpha=0.72$ ); and major violence (verbal threats directed towards teachers, physical assaults between students, physical assaults directed at teachers, carrying weapons in school; $\alpha=0.77$ ).

\section{Measures: outcomes (15.7 years, grade 10 )}

Outcome measures include indicators of antisocial behaviour (drug use, delinquency), emotional distress (depressive symptoms, social anxiety) and academic adjustment (school achievement and school engagement). ${ }^{23-28}$

Drug use was measured using a 4 -item scale $(\alpha=0.75)$ on frequency of alcohol intoxication, as well as the use of cannabis, stimulants or hallucinogens, and hard drugs in the past 12 months. ${ }^{24}$ Responses range from never $(=0)$ to very often $(=0)$ and were averaged.

Delinquency was assessed by summing students' responses to 16 items $(\alpha=0.95)$ addressing the occurrence of behaviours associated with conduct disorder in the past 12 months (ie, theft, vandalism, threats, extortion, physical violence, runaway, youth gang involvement, carrying weapons). ${ }^{24}$ Responses range from never $(=0)$ to very often $(=0)$.

Social anxiety was assessed using the 6-item subscale $(\alpha=0.81)$ from the Spence Children's Anxiety Scale (eg, I worry about what others think of me). ${ }^{25}$ Responses ranged from never $(=0)$ to always $(=3)$ and were averaged.

Depressive symptoms were assessed using the Center for Epidemiologic Studies-Depression questionnaire, a 15-item scale $(\alpha=0.90)$ that asks participants to report the frequency of sad or depressive symptoms over the past week (eg, I thought my life had been a failure). ${ }^{23} 26$ Summed responses range from rarely $(=0)$ to most of the time or always $(=3)$.

School achievement was assessed using mean self-reported percentage grades in Mathematics and Language Arts (French or English, depending on the school attended). ${ }^{27}$

School engagement was measured using a tridimensional measure including behavioural, cognitive and affective dimensions. ${ }^{28}$ Items and scales were combined using standardised $\mathrm{Z}$ scores and weights from a confirmatory factor analysis described in a previous study. ${ }^{27}$ Responses range from never or not at all $(=0)$ to always or extremely $(=3)$.

\section{Measures: pre-existing and concurrent control variables}

Three categories of potential confounders were self-reported by participants. (1) Victimisation at age 13.4 years (grade 8 ). 
Specifically, the experience of direct violence was measured at the same time as witnessing school violence using the average frequency of a 9-item victimisation scale (eg, theft, insult or humiliation, verbal threat, extortion, physical attack, and threat or assault with a weapon by student, threat of assault by members of gangs, insult or humiliation and physical aggression by staff member) during the school year. ${ }^{10}$ Responses range from never $(=0)$ to 4 times or more $(=4)$. (2) Pre-existing measures at age 12.8 years (grade 7). These included drug use, delinquency, depression, anxiety, achievement and engagement. (3) Sociodemographic, individual, family and peer characteristics at age 12.8 years (grade 7). Individual characteristics included sex $(0=$ female; $1=$ male $)$, place of birth $(0=$ Quebec born; $1=$ other $)$; performance on a fluid intelligence test (Raven's Standard Progressive Matrices), ${ }^{28}$ grade retention in elementary school $(0=$ none; $1=$ grade retention once or more). Family characteristics included adversity (a cumulative index of 9 parental risk factors: low family wealth, low home educational resources, low maternal and paternal education and occupational prestige, single-parent family configuration, household moves in the past 5 years, siblings not having completed high school), parent-child communication (six items; eg, Do you share your thoughts and feelings with your parents? $\alpha=0.85),{ }^{24}$ parent-child conflict (three items; eg, Do you ever fight or argue with your parents? $\alpha=0.73)^{24}$ and parental supervision (two items; eg, Do your parents know where you are when you're out of the house? $\alpha=0.80) .{ }^{24}$ Responses for these three scales ranged from never $(=0)$ to always $(=3)$ and were averaged. Peer characteristics included peer deviancy (three items; eg, My best friends could have been in trouble with the police because of certain things they did, $0=$ strongly disagree to $4=$ strongly agree, $\alpha=0.68)^{24}$ and peer school disengagement (three items; eg, My best friends often talk about dropping out of school, $\alpha=0.63) .{ }^{24}$ Responses ranged from not really true $(=0)$ to certainly true $(=4)$ and were averaged.

\section{Data analysis strategy}

Ordinary least squares regression was used to estimate the association between witnessing school violence at age 13 and subsequent psychosocial outcomes at age 15 . The 'type $=$ complex' option in Mplus V.6.12 $2^{29}$ was used to adjust for school nesting and dependence of observations. We first regressed psychosocial outcomes on witnessing general violence (model 1), followed by separate estimations of the relationship for each specific type of violence (covert, minor, major) in separate models (models 2-4). For each model, pre-existing and concurrent control variables, as well as the predictor, were entered simultaneously.

All self-report data on witnessing violence were complete. To retain all available participants and reduce potential attrition bias (see online supplementary appendices A and B), we corrected for incomplete outcome and control variable data by using full information maximum likelihood (FIML) estimation. Estimation by FIML allows to preserve sample size and reduce potential attrition bias using information from the existing control variables. ${ }^{30}$ Furthermore, to compare the influence of missing data treatment on results, we conducted parallel analyses using listwise deletion. Results did not differ for any of the outcomes of the study (and are available on request).

\section{RESULTS}

\section{Descriptive analyses}

Table 1 reports descriptive statistics and correlations for the variables in this study. Correlations between covert, minor and major violence were high $(\mathrm{r}=0.50-0.61)$, but not high enough to preclude conceptualising these variables as distinct aspects of a larger construct. Witnessing school violence at age 13 was correlated with each psychosocial outcome at age 15. Almost all participants (97\%) reported witnessing school violence in one form or another at age 13 . Witnessing covert, minor and major violence was respectively reported by $78 \%, 96 \%$ and $77 \%$ of participants. Thus, not only was witnessing school violence extremely prevalent, the vast majority of students reported witnessing at least one major violent event at school. In comparison, $31 \%, 59 \%$ and $24 \%$ of participants respectively reported being victim of covert, minor and major violence. Figure 1 compares the prevalence of witnessing versus being the direct victim of covert, minor and major violence at school. As expected, based on comparable scale items, participants were considerably more likely to be involved as witnesses than as direct victims for each type of violent event.

\section{Inferential analyses}

Table 2 documents the adjusted regression coefficients (unstandardised and standardised) comparing the relationship between witnessing total (model 1), covert (model 2), minor (model 3) and major (model 4) school violence at age 13 and subsequent internalising problems, externalising problems and academic adjustment at age 15 . These are four separate distinct regression models. Model 1 indicates that witnessing all types of violence at age 13 predicted drug use $(\beta=0.09)$, delinquency $(\beta=0.07)$ and marginally predicted subsequent social anxiety $(B=0.04)$ and depressive symptoms $(B=0.05)$ at age 15 . Although witnessing school violence did not predict academic achievement, it was associated with lower academic engagement $(B=-0.06)$. All analyses were adjusted for pre-existing individual and family sociodemographic characteristics (at age 12) and individual experiences of victimisation (at age 13).

As for the contribution of different types of school violence, witnessing covert and major school violence showed significant associations with later drug use and delinquency. Witnessing covert (model 2) was associated with a greater risk of drug use $(\beta=0.07)$. Major (model 4$)$ school violence showed a comparatively larger association with drug use $(\beta=0.09)$ and delinquency $(\Omega=0.11)$ risk than witnessing minor violence (model 3$)$. The reverse pattern was found for emotional distress and academic adjustment. Witnessing minor, but not covert or major violence was associated with increases in social anxiety $(\beta=0.05)$, depressive symptoms $(\beta=0.06)$ and decreases in academic engagement $(ß=-0.06)$.

Regression coefficients for victimisation allow us to estimate the relative contributions of both witnessing school violence and direct exposure, at age 13, to subsequent adolescent adjustment, compared with concurrent victimisation experiences. Victimisation was not associated with subsequent drug use and was only predictive of delinquency ( $\beta=0.07 ; 95 \%$ CI 0.0 to 0.14 ), However, victimisation predicted both social anxiety $(\beta=0.09$; $95 \%$ CI 0.05 to 0.14$)$ and depressive symptoms $(\beta=0.11$; 95\% CI 0.04 to 0.17), with larger effect sizes than witnessing violence. Victimisation did not predict academic achievement or school engagement.

\section{DISCUSSION}

From a bystander or spectator vantage point, school violence represents a public health hazard because of its potential for psychologically affecting an exponential number of people. ${ }^{5}$ What is more, it might influence self-perceptions that society 
Table 1 Descriptive statistics and correlations for the variables in this study

\begin{tabular}{|c|c|c|c|c|c|c|c|c|c|c|c|c|}
\hline & 17 & 18 & 19 & 20 & 21 & 22 & 23 & 24 & 25 & 26 & M & SD \\
\hline Sex* & & & & & & & & & & & 0.48 & 0.50 \\
\hline Place of birth* & & & & & & & & & & & 0.05 & 0.21 \\
\hline Family adversity & & & & & & & & & & & 1.57 & 1.53 \\
\hline Abstract reasoning (Raven's Matrices) & & & & & & & & & & & 56.77 & 27.15 \\
\hline Grade retention in elementary school* & & & & & & & & & & & 0.15 & 0.41 \\
\hline Communication with parents (age 12) & & & & & & & & & & & 2.11 & 0.68 \\
\hline Parental supervision (age 12) & & & & & & & & & & & 2.14 & 0.83 \\
\hline Conflict with parents (age 12) & & & & & & & & & & & 1.08 & 0.63 \\
\hline Peer deviancy (age 12) & & & & & & & & & & & 0.60 & 0.93 \\
\hline Peer academic disengagement (age 12) & & & & & & & & & & & 1.32 & 0.49 \\
\hline School achievement (age 12) & & & & & & & & & & & 75.84 & 10.75 \\
\hline School engagement (age 12) & & & & & & & & & & & 0.07 & 0.57 \\
\hline Drug use (age 12) & & & & & & & & & & & 0.18 & 0.43 \\
\hline Delinquency (age 12) & & & & & & & & & & & 2.33 & 5.14 \\
\hline Social anxiety (age 12) & & & & & & & & & & & 1.17 & 0.66 \\
\hline Depressive symptoms (age 12) & & & & & & & & & & & 7.40 & 7.62 \\
\hline Victimisation (age 13) & & & & & & & & & & & 0.43 & 0.59 \\
\hline Witnessing total violence (age 13) & 0.42 & & & & & & & & & & 1.17 & 0.72 \\
\hline Witnessing covert violence (age 13) & 0.31 & 0.78 & & & & & & & & & 0.96 & 0.87 \\
\hline Witnessing minor violence (age 13) & 0.32 & 0.86 & 0.55 & & & & & & & & 1.88 & 1.01 \\
\hline Witnessing major violence (age 13) & 0.43 & 0.85 & 0.57 & 0.55 & & & & & & & 0.66 & 0.74 \\
\hline School achievement (age 15) & -0.08 & -0.02 & -0.02 & 0.01 & -0.05 & & & & & & 73.33 & 9.64 \\
\hline School engagement (age 15) & -0.11 & -0.13 & -0.08 & -0.12 & -0.10 & 0.30 & & & & & 0.03 & .58 \\
\hline Drug use (age 15) & 0.13 & 0.16 & 0.12 & 0.11 & 0.16 & -0.17 & -0.40 & & & & 0.56 & 0.64 \\
\hline Delinquency (age 15) & 0.18 & 0.16 & 0.14 & 0.06 & 0.21 & -0.17 & -0.34 & 0.58 & & & 3.16 & 6.95 \\
\hline Social anxiety (age 15) & 0.09 & 0.06 & 0.04 & 0.09 & 0.01 & 0.04 & 0.15 & -0.01 & -0.02 & & 1.18 & 0.65 \\
\hline Depressive symptoms (age 15) & 0.17 & 0.13 & 0.09 & 0.13 & 0.10 & -0.10 & -0.18 & 0.28 & 0.33 & 0.35 & 7.49 & 8.42 \\
\hline
\end{tabular}

Significant correlations $(p<0.05)$ in bold.

* Male, students born out of Canada, repeaters and dropouts were coded as 1.

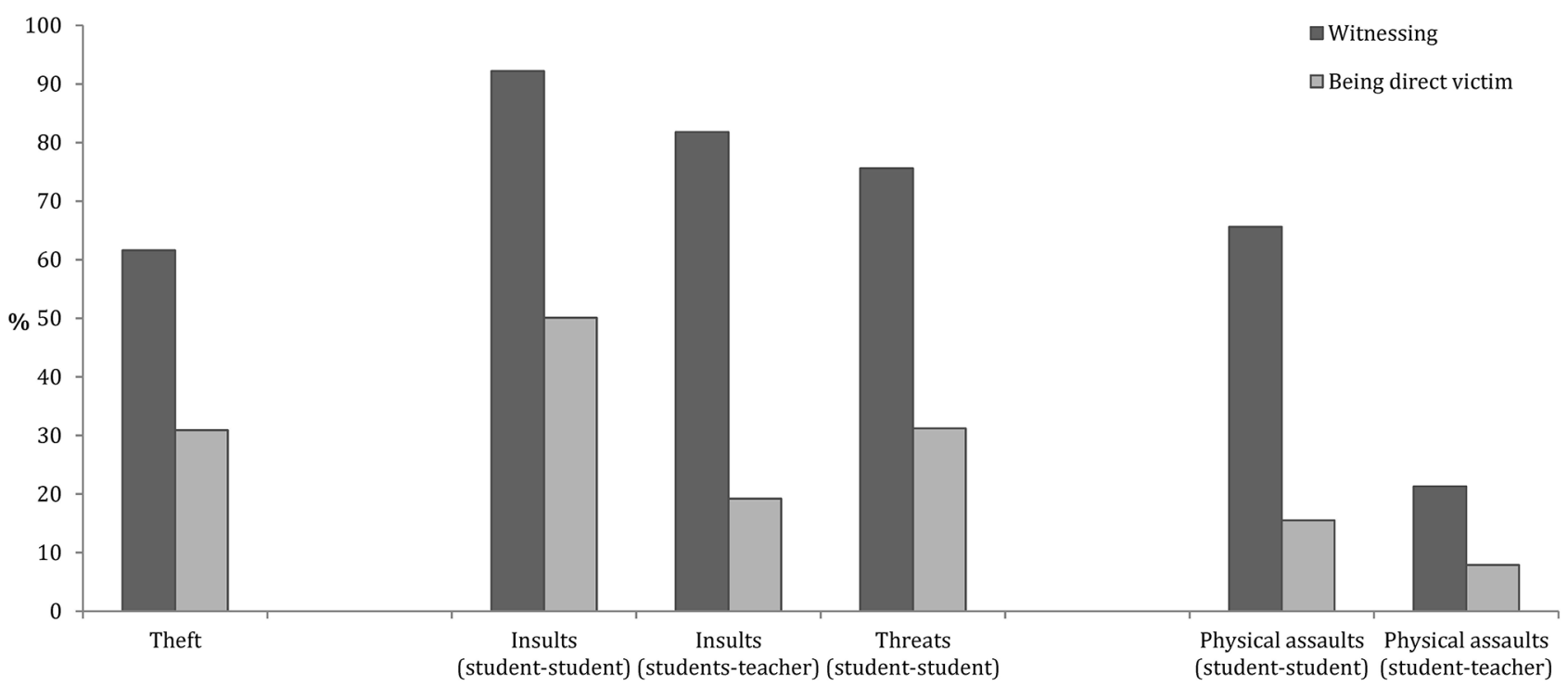

Covert

$\underline{\text { Minor }}$

\section{$\underline{\text { Major }}$}

Figure 1 Comparison of witnessing versus being the direct victim of covert, minor and major violent events at school, based on comparable scale items. 
Table 2 Adjusted prospective associations (unstandardised and standardised regression coefficients) between witnessing total, covert, minor and major school violence at age 13 and internalising problems, externalising problems and academic adjustment at age 15

\begin{tabular}{|c|c|c|c|c|c|}
\hline Outcome (age 15) & Model & Predictor (age 13) & Adjustedt B (SE) & Adjustedt B $(95 \% \mathrm{Cl})$ & Model $\mathrm{R}^{2}$ \\
\hline \multicolumn{6}{|l|}{ Antisocial behaviour } \\
\hline \multirow[t]{3}{*}{ Drug use } & 1 & Witnessing total violence & $0.08(0.02)^{* * *}$ & 0.09 (0.04 to 0.14$)$ & 0.16 \\
\hline & 3 & Witnessing minor violence & $0.04(0.01)^{*}$ & 0.05 (0.01 to 0.10$)$ & 0.16 \\
\hline & 4 & Witnessing major violence & $0.08(0.02)^{* * *}$ & 0.09 (0.04 to 0.14$)$ & 0.16 \\
\hline \multirow[t]{3}{*}{ Delinquency } & 1 & Witnessing total violence & $0.64(0.25)^{*}$ & 0.07 (0.02 to 0.12$)$ & 0.16 \\
\hline & 3 & Witnessing minor violence & $0.03(0.14)$ & $0.00(-0.04$ to 0.04$)$ & 0.17 \\
\hline & 4 & Witnessing major violence & $1.01(0.30)^{* * *}$ & $0.11(0.05$ to 0.17$)$ & 0.16 \\
\hline \multicolumn{6}{|l|}{ Emotional distress } \\
\hline \multirow[t]{2}{*}{ Social anxiety } & 1 & Witnessing total violence & $0.04(0.02) \ddagger$ & 0.04 (0.00 to 0.09 ) & 0.25 \\
\hline & 2 & Witnessing covert violence & $0.02(0.01) \ddagger$ & $0.03(0.00$ to 0.06$)$ & 0.25 \\
\hline \multirow{3}{*}{ Depressive symptoms } & 2 & Witnessing covert violence & $0.36(0.23)$ & $0.04(-0.01$ to 0.08$)$ & 0.12 \\
\hline & 3 & Witnessing minor violence & $0.46(0.16)^{* *}$ & .006 (0.02 to 0.09$)$ & 0.11 \\
\hline & 4 & Witnessing major violence & $0.56(0.31) \ddagger$ & $0.05(0.00$ to 0.10$)$ & 0.11 \\
\hline \multicolumn{6}{|l|}{ Academic adjustment } \\
\hline \multirow[t]{4}{*}{ School achievement } & 1 & Witnessing total violence & $0.44(0.32)$ & $0.03(-0.01$ to 0.08$)$ & 0.35 \\
\hline & 2 & Witnessing covert violence & $0.13(0.26)$ & $0.01(-0.03$ to 0.06$)$ & 0.35 \\
\hline & 3 & Witnessing minor violence & $0.22(0.21)$ & $0.02(-0.02$ to 0.07$)$ & 0.35 \\
\hline & 4 & Witnessing major violence & $0.46(0.28)$ & $0.04(-0.01$ to 0.08$)$ & 0.35 \\
\hline \multirow[t]{2}{*}{ School engagement } & 1 & Witnessing total violence & $-0.05(0.02)^{*}$ & $-0.06(-0.10$ to -0.01$)$ & 0.22 \\
\hline & 2 & Witnessing covert violence & $-0.02(0.01) \ddagger$ & $-0.04(-0.07$ to 0.00$)$ & 0.22 \\
\hline
\end{tabular}

${ }^{*} \mathrm{P}<0.05 ;{ }^{* *} \mathrm{P}<0.01 ;{ }^{* * *} \mathrm{P}<0.001$.

†All models are adjusted for concurrent victimisation at age 13, child sex and place of birth, as well as baseline values (at age 12) for family adversity, fluid intelligence, grade retention in elementary school, communication with parents, parental supervision, conflict with parents, peer deviancy and peer school disengagement. $\ddagger \mathrm{P}<0.10$.

is violent, which diminishes mental estimates of community efficacy and safety. ${ }^{31}$ This large-scale longitudinal study offers interesting insights, based on Canadian data, where the social safety net, healthcare and other economic policies are substantially progressive and are more comparable to Europe than to the USA. ${ }^{32}$ The take home lesson seems to be that despite the large network of protective social policies, school violence is remarkably prevalent and disturbing, even to non-participants on the sidelines.

First, witnessing school violence seems statistically normative for adolescents in typical schools. Almost all of the participants in our sample witnessed violence in one form or another in middle school. A clear majority reported witnessing at least one major violent event such as a physical assault.

Youth who witnessed violent events at age 13 were at subsequent risk of psychosocial impairment at age 15. This finding accounted for prior direct experiences of victimisation, functioning and sociodemographic confounders that were concurrently measured with the outcomes. Relative to direct victimisation, witnessing school violence presented similar risks of subsequent delinquency. This is even more visible when covert and major violence are considered. This suggests that, seeing violence happen might have a comparable deleterious impact as experiencing it directly when it comes to later conduct disorder symptom outcomes such as inflicting harm on others, truancy, theft and vandalism. This finding warrants further investigation.

Several unexpected findings are noteworthy. The psychological strain of simply being exposed, treated as a general variable, was only expressed through subsequent conduct problems but not depressive or anxious symptoms. Similarly, general exposure to violence, either directly or as a witness, was not associated with achievement. A likely explanation is that academic achievement is more strongly tied to factors such as working memory, classroom engagement and pre-existing cognitive skills. ${ }^{33} \mathrm{No}$ observed relation with our two indicators of emotional distress might also account for the absence of a link.

Most importantly, to our knowledge, studies had yet to examine responses to witnessing distinct levels of school violence. Our results suggest that there are different responses associated with each level of violence severity experienced by students. Involvement in drug taking and delinquency was primarily associated with prior witnessing covert and major violence. This is plausible given that in many situations, covert violence can be as intense and have similar motives as major violence. ${ }^{31}$ Covert violence is simply hidden from observation and coherent with drug use or delinquent behaviour, which are mostly covert as well. Witnessing minor violence was associated with both social anxiety and depressive symptoms (as an internal 
distress response) and school disengagement (as an external social distress response). We can speculate that these might be individual coping mechanisms that aim to emotionally regulate oneself and attenuate attention from others in an environment perceived as aggressive. Such differential predictions may also help clarify the psychological mechanisms by which indirect violence leads to dysfunctional adolescent outcomes.

We have previously interpreted witnessing school violence as inducing feelings of fear and insecurity that give rise to either a fight or a flight response in bystander students. ${ }^{10}$ Consistent with this interpretation, witnessing violent events that reach a certain level of severity or threat (ie, covert or major violence) may primarily elicit fight responses, which can take the form of conduct problems. Witnessing covert and major violence may also contribute to delinquency via modelling and cognitive normalisation of deviant behaviour ${ }^{34}$ or emotional desensitisation to violence, ${ }^{35}$ and to substance use via a mechanism in which drugs serve as a coping strategy in response to psychological difficulty. ${ }^{36}$ Less severe, but more frequent and chronic and interpersonal violent events (ie, minor violence) may primarily elicit flight responses in the form of emotional distress and disengagement from the school setting. It could be that such flight responses, in the form of ignoring or giving messages of tolerance to minor violence to others, evoke feelings of guilt, which is manifested by emotionally distressed behaviour. It is also plausible that prolonged indirect exposure to minor violence may contribute to emotional distress by undermining relational climate in the school context. ${ }^{37}$

Despite its prospective design with numerous participants, this study should be interpreted in light of several limitations. First, all information was obtained via self-report. The observed associations may partly reflect reporting bias and shared method variation. ${ }^{38}$ The intercorrelations between the predictor and control and outcome variables were mostly modest. This, in addition to the number of control variables and participant attrition, may explain the low standardised regression coefficients. Second, although we did control for experiencing victimisation at the same time as witnessing school violence, we did not adjust for direct perpetration of violence. Baseline delinquency may be argued to represent a good proxy of this construct in all models. Finally, the sample comprised a majority of students from disadvantaged areas. Results may thus not generalise to all types of schools given that school violence is more frequent in underprivileged schools, even in a generous social policy context like Canada. ${ }^{9}$

Future studies should seek to further clarify the underlying mechanisms by which witnessing school violence predicts longterm adolescent outcomes after the stressful event(s). Several explanations have been tested so far (eg, feelings of insecurity, emotional desensitisation). ${ }^{10} 35$ Studies need to consider the type of school violence witnessed by students when probing underlying mechanisms that generate psychological responses. Investigators should also explore factors that protect against the psychosocial risks associated with witnessing school violence. Individual characteristics such as gender and age and schoollevel characteristics such as school size and organisation represent relevant candidate mitigating factors to explore. ${ }^{36}$

Clearly, exposure to school violence affects a vast majority of secondary school students, many of whom are not direct victims of violence. Indirect violence represents a long-term developmental risk for subsequent mental health problems. Comprehensive and universal approaches towards the prevention of school violence are warranted. These approaches should include witnesses as well as victims and perpetrators and target all forms of school violence, including acts of covert and minor violence. ${ }^{39}{ }^{40}$ Nevertheless, prevention is not always effective, which leads to concerns for victims and bystanders. Given the frequency of violence in schools, actively supportive family and community relationships represent important resources for facilitating coping strategies after having been exposed to events associated that inflict psychological or physical harm. ${ }^{31}$ These also prevent emotional desensitisation to violence which also contributes to aggressive behaviour in youth. ${ }^{34}$ We contend that postviolence intervention programmes would benefit from a population-based approach that normalises concern for others and intolerance for disrespect, seeks to empower bystander students who are not directly involved in acts of school violence and publicly activates protective relationships.

\section{What is already known on this subject}

- Previous studies suggest that adolescents who witness violence in secondary school are at risk of experiencing adjustment problems. However, few studies have used a long-term prospective design and have accounted for direct experiences of school violence (victimisation) and other major confounders.

\section{What this study adds}

- Youth who witnessed violent school events at age 13 were at subsequent risk of psychosocial and academic impairment at age 15. Later involvement in drug taking and delinquency was primarily associated with witnessing earlier covert and major violence. Later emotional distress and disengagement from school were associated with witnessing earlier minor violence. The associations between indirectly experiencing violence as a bystander and subsequent impairment were comparable to those of direct violence.

Contributors MJ directed the data collection, conceptualised the study and drafted the manuscript. FNB helped conceptualise the study and conduct the analyses, and wrote a first draft of the manuscript. SP conducted the analyses and revised the manuscript. BG helped conceptualise the study and the analytical procedure, and revised the manuscript. IA participated in data collection and revised the manuscript. MCB, BM and LSP helped conceptualise the study and revised the manuscript. All authors approved the final manuscript as submitted and agree to be accountable for all aspects of the work.

Funding Analyses were funded by a public team grant awarded by the Fonds de recherche du Québec-Société et culture (FRQSC No 136876).

Competing interests None declared.

Patient consent Not required.

Ethics approval Ethics Committee/Institutional Review Board approval obtained by Université de Montréal.

Provenance and peer review Not commissioned; externally peer reviewed.

Data sharing statement Used and unused data are available for consultation upon request to the first author.

\section{REFERENCES}

1 Benbenishty R, Astor RA. School violence in an international context: a call for global collaboration in research and prevention. Int J Violence Sch 2006;7:59-80.

2 Due P, Holstein BE, Lynch J, et al. Bullying and symptoms among school-aged children: international comparative cross sectional study in 28 countries. Eur J Public Health 2005; 15:128-32.

3 Morgan RE, Musu-Gillette L, Robers S, et al. Indicators of School Crime and Safety: 2014. Bureau of Justice Statistics 2015. 2015. http://www.bjs.gov/index.cfm?ty= pbdetail\&iid=5322\&utm_source=juvjust-071315\&utm_medium=email\&utm_ 
content=Indicators\%20of\%20School\%20Crime\%20and\%20Safety\%202014\&utm_ campaign=juvjust

4 Arseneault L. The long-term impact of bullying victimization on mental health. World Psychiatry 2017;16:27-8

5 Singer MI, Anglin TM, Song LY, et al. Adolescents' exposure to violence and associated symptoms of psychological trauma. JAMA 1995;273:477-82.

6 Erskine HE, Norman RE, Ferrari AJ, et al. Long-term outcomes of attention-deficit/ hyperactivity disorder and conduct disorder: a systematic review and meta-analysis. J Am Acad Child Adolesc Psychiatry 2016;55:841-50.

7 Evensen M, Lyngstad TH, Melkevik O, et al. Adolescent mental health and earnings inequalities in adulthood: evidence from the Young-HUNT Study. J Epidemiol Community Health 2017;71:201-6.

8 McLeod GFH, Horwood L, Fergusson DM, et al. adult mental health and psycho-social outcomes at 30 and 35 years. Psych Med 2016;46:1401-12.

9 Flannery DJ, Wester KL, Singer MI. Impact of exposure to violence in school on child and adolescent mental health and behavior. J Community Psychol 2004;32:559-73.

10 Janosz M, Archambault I, Pagani LS, et al. Are there detrimental effects of witnessing school violence in early adolescence? J Adolesc Health 2008;43:600-8.

11 Mrug S, Windle M. Prospective effects of violence exposure across multiple contexts on early adolescents' internalizing and externalizing problems. J Child Psychol Psychiatry 2010;51:953-61.

12 Reitz AK, Motti-Stefanidi F, Asendorpf JB. Me, us, and them: testing sociometer theory in a socially diverse real-life context. J Pers Soc Psychol 2016;110:908-20.

13 Wölfer R, Schmid K, Hewstone M, et al. Developmental dynamics of intergroup contact and intergroup attitudes: long-term effects in adolescence and early adulthood. Child Dev 2016:87:1466-78.

14 Becht Al, Nelemans SA, Branje SJT, et al. The quest for identity in adolescence: Heterogeneity in daily identity formation and psychosocial adjustment across 5 years. Dev Psychol 2016;52:2010-21.

15 O'Keefe M. Adolescents' exposure to community and school violence: prevalence and behavioral correlates. J Adolesc Health 1997;20:368-76.

16 Ramirez M, Wu Y, Kataoka S, et al. Youth violence across multiple dimensions: a study of violence, absenteeism, and suspensions among middle school children.J Pediatr 2012;161:542-6.

17 Rivers I, Noret N. Participant roles in bullying behavior and their association with thoughts of ending one's life. Crisis 2010;31:143-8.

18 Swearer SM, Hymel S. Understanding the psychology of bullying: Moving toward a social-ecological diathesis-stress model. Am Psychol 2015;70:344-53.

19 Deane K, Richards M, Mozley M, et al. Posttraumatic stress, family functioning, and externalizing in adolescents exposed to violence: a moderated mediation model. J Clin Child Adolesc Psychol 2016:3:1-4.

20 Berkowitz R, Moore $\mathrm{H}$, Astor RA, et al. A research synthesis of the associations between socioeconomic background, inequality, school climate, and academic achievement. Rev Educ Res 2017;87:425-69.

21 Mayer MJ, Furlong MJ. How safe are our schools? Educ Researcher 2010;39:16-26.

22 Janosz M, Pascal S, Galand B. Être témoin de violence à l'école: son importance et ses liens avec le climat scolaire (Witnessing violence in school: its importance and association with school climate). In: Galand B, Carra C, Verhoeven M, eds. Prévenir les violences à l'école (Preventing Violence in Schools). Paris: Presses universitaires de France, 2012:93-109.

23 Brière FN, Janosz M, Fallu JS, et al. Adolescent trajectories of depressive symptoms: codevelopment of behavioral and academic problems. J Adolesc Health 2015;57:313-9.

24 Morizot J. Construct validity of adolescents' self-reported big five personality traits: importance of conceptual breadth and initial validation of a short measure. Assessment 2014;21:580-606.

25 Radloff LS. The CES-D Scale: a self-report depression scale for research in the general population. Applied Psychol Meas 1977;1:385-401.

26 Spence SH. Structure of anxiety symptoms among children: a confirmatory factoranalytic study. J Abnorm Psychol 1997;106:280-97.

27 Archambault I, Janosz M, Morizot J, et al. Adolescent behavioral, affective, and cognitive engagement in school: relationship to dropout. I Sch Health 2009;79:408-15.

28 Pagani LS, Brière FN, Janosz M. Fluid reasoning skills at the high school transition predict subsequent dropout. Intelligence 2017;62:48-53.

29 Muthén LK, Muthén BO. Mplus user's guide. 6th edn. Los Angeles, CA: Muthén \& Muthén:1998-2010.

30 Graham JW. Missing data analysis: making it work in the real world. Annu Rev Psychol 2009;60:549-76.

31 Ozer EJ, Lavi I, Douglas L, et al. Protective factors for youth exposed to violence in their communities: a review of family, school, and community moderators. I Clin Child Adolesc Psychol 2017;46:353-78.

32 Porter J. The vertical mosaic: an analysis of social class and power in Canada: University of Toronto Press, 2015.

33 Pagani LS, Fitzpatrick C, Archambault I, et al. School readiness and later achievement: a French Canadian replication and extension. Dev Psychol 2010;46:984-94.

34 Guerra NG, Huesmann LR, Spindler A. Community violence exposure, social cognition, and aggression among urban elementary school children. Child Dev 2003;74:1561-76

35 Mrug S, Madan A, Windle M. Emotional desensitization to violence contributes to adolescents' violent behavior. J Abnorm Child Psychol 2016;44:75-86.

36 Benbenishty R, Astor RA, Roziner I, et al. Testing the causal links between school climate, school violence, and academic performance: a cross-lagged panel autoregressive model. Edu Res 2016;45:197-206.

37 Brière FN, Pascal S, Dupéré V, et al. School environment and adolescent depressive symptoms: a multilevel longitudinal study. Pediatrics 2013;131:e702-8.

38 Siemsen E, Roth A, Oliveira P. Common method bias in regression models with linear, quadratic, and interaction effects. Organ Res Methods 2010;13:456-76.

39 Bradshaw CP. Translating research to practice in bullying prevention. Am Psychol 2015;70:322-32.

40 Roberts NP, Roberts PA, Jones N, et al. Psychological interventions for post-traumatic stress disorder and comorbid substance use disorder: a systematic review and metaanalysis. Clin Psychol Rev 2015;38:25-38. 